\title{
Successful Slow Desensitization to Tocilizumab in a 15-Year-Old Patient
}

Cansever $\mathrm{M}^{1}$, Şahin $\mathrm{N}^{2}$, Dursun $\mathrm{I}^{2}$, Geyik $\mathrm{C}^{3}$, Düşünsel R², Bektaş Kut $\mathrm{F}^{1}$, Tahan $\mathrm{F}^{1}$

${ }^{1}$ Erciyes University, School of Medicine, Department of Pediatrics, Division of Allergy, Kayseri, Turkey

${ }^{2}$ Erciyes University, School of Medicine, Department of Pediatrics, Division of Rheumatology, Kayseri, Turkey

${ }^{3}$ Erciyes University, School of Medicine, Department of Pediatrics, Kayseri, Turkey

J Investig Allergol Clin Immunol 2018; Vol. 28(6): 436-438 doi: $10.18176 /$ jiaci.0314

Key words: Anaphylaxis. Allergic reactions. Desensitization. Juvenile idiopathic arthritis. Tocilizumab.

Palabras clave: Anafilaxia. Reacciones alérgicas. Desensibilización. Artritis idiopática juvenile. Tocilizumab.

Systemic juvenile idiopathic arthritis (sJIA) is a polygenic autoinflammatory disease and the most common cause of arthritis in children and adolescents [1]. Macrophage activation syndrome is the most challenging adverse effect. IL-6 is involved in the pathophysiology of macrophage activation syndrome. Tocilizumab is a biologic agent approved for the treatment of rheumatoid arthritis (RA) in adults, polyarticular juvenile rheumatoid arthritis, and the systemic form of juvenile idiopathic arthritis in children. Tocilizumab blocks the IL-6 receptor in order to discontinue production of inflammation in the body. It is approved in Europe and the USA for the treatment of moderate to severe RA in adult patients who have responded inadequately or been intolerant to previous therapy with 1 or more diseasemodifying antirheumatic drugs or tumor necrosis factor inhibitors [2]. Anaphylactic adverse effects have been reported for tocilizumab, and incidence has been increasing over time [3].

A 15 -year-old boy presented 9 months ago with progressive pain in the neck, left knee, and back. He had concurrent fever and rash starting on the palms and spreading all over the body. Given the persistent fever, epistaxis, and bicytopenia, he was diagnosed with macrophage activation syndrome and underwent bone morrow aspiration. Hemophagocytosis was seen in 2 separate samples. Therefore, the patient was diagnosed as having JIA. As pulse methylprednisolone treatment was ineffective, tocilizumab was considered after treatment with intravenous immunoglobulin. The infusion was commenced at $600 \mathrm{mg}$ every 2 weeks. After the second dose, the patient developed pruritus, maculopapular rash, angioedema, and dyspnea and was diagnosed with grade 2 anaphylaxis [4]. The tocilizumab infusion was stopped, and epinephrine $(0.01 \mathrm{mg} / \mathrm{kg})$ and pheniramine maleate $(1 \mathrm{mg} / \mathrm{kg})$ were administered. The treatment protocol was withdrawn for 2 weeks. 
Table. Desensitization Solutions and Protocol

\begin{tabular}{|c|c|c|c|c|c|c|}
\hline & \multicolumn{2}{|c|}{$\begin{array}{r}\text { Volume, } \\
\mathrm{mL}\end{array}$} & $\begin{array}{r}\text { Total Drug } \\
\text { Dose per } \\
\text { Solution }\end{array}$ & \multicolumn{2}{|c|}{$\begin{array}{r}\text { Concentration, } \\
\mathrm{mg} / \mathrm{mL}\end{array}$} & $\begin{array}{r}\text { Total } \\
\text { Infused } \\
\text { Volume }\end{array}$ \\
\hline \multicolumn{2}{|c|}{ Solution 1} & 250 & $6 \mathrm{mg}$ & & 0.024 & $15 \mathrm{~mL}$ \\
\hline \multicolumn{2}{|c|}{ Solution 2} & 250 & $60 \mathrm{mg}$ & & 0.24 & $24 \mathrm{~mL}$ \\
\hline \multicolumn{2}{|c|}{ Solution 3} & 250 & $600 \mathrm{mg}$ & & 2.4 & $250 \mathrm{~mL}$ \\
\hline Step & Solution & $\begin{array}{l}\text { Infusion } \\
\text { rate, } \\
\mathrm{mL} / \mathrm{h}\end{array}$ & $\begin{array}{c}\text { Time, } \\
\min \end{array}$ & $\begin{array}{l}\text { Volume, } \\
\text { mL }\end{array}$ & $\begin{array}{l}\text { Dosage } \\
\text { Adminis- } \\
\text { tered This } \\
\text { Step, mg }\end{array}$ & $\begin{array}{c}\text { Cumula- } \\
\text { tive } \\
\text { Dose, } \\
\text { mg }\end{array}$ \\
\hline 1 & 1 & 4 & 15 & 1 & 0.024 & 0.024 \\
\hline 2 & 1 & 8 & 15 & 2 & 0.048 & 0.072 \\
\hline 3 & 1 & 16 & 15 & 4 & 0.096 & 1.032 \\
\hline 4 & 1 & 32 & 15 & 8 & 0.192 & 1.224 \\
\hline 5 & 2 & 6.4 & 15 & 1.6 & 0.384 & 1.608 \\
\hline 6 & 2 & 12.8 & 15 & 3.2 & 0.768 & 2.376 \\
\hline 7 & 2 & 25.6 & 15 & 6.4 & 1.536 & 3.912 \\
\hline 8 & 2 & 51.2 & 15 & 12.8 & 3.072 & 6.984 \\
\hline 9 & 3 & 10 & 15 & 2.5 & 6.144 & 13.128 \\
\hline 10 & 3 & 20 & 15 & 5 & 12.288 & 25.416 \\
\hline 11 & 3 & 40 & 15 & 10 & 24.576 & 49.992 \\
\hline 12 & 3 & 80 & 180 & 230 & 550 & 600 \\
\hline
\end{tabular}

The result of skin prick testing with varying concentrations of tocilizumab $(1 / 100,1 / 10$, and $1 / 1)$ was negative; that of intradermal testing with a $1 / 1$ concentration was positive.

Given the lack of alternative medication, tocilizumab was the only choice for the patient, who therefore underwent desensitization before the third infusion.

A 12-step desensitization schedule was planned to achieve a total therapeutic dose of $600 \mathrm{mg}$ (Table). Premedication was with methylprednisolone, hydroxyzine, and ranitidine, respectively, 13, 7, and 1 hour before the desensitization procedure. He tolerated the full therapeutic dose with no adverse effects. The maintenance dose $(600 \mathrm{mg})$ is now supervised twice weekly by the nephrology department.

Three solutions with different concentrations were administered (Table) [5]. The initial solution was tocilizumab $0.024 \mathrm{mg}$ infused in 15 minutes (1/25000 of total dose).

The infusion rate was increased at 15-minute intervals. A cumulative dose of $1.224 \mathrm{mg}$ had been administered in the first hour of desensitization. The rate increased to 98.28 $\mathrm{mg} / \mathrm{h}$ after 165 minutes. A constant rate of $196.56 \mathrm{mg} / \mathrm{h}$ was maintained until the infusion ended (Table) [5]. Total infusion time was 5 hours 45 minutes. A resident and a nurse monitored the patient throughout the infusion. Vital signs were assessed every 15 minutes. The patient was hospitalized for another 24 hours to monitor adverse effects.

The patient has received 2 additional tocilizumab infusions to date, with no adverse effects. Following the sensitization regimen, there is no need for additional desensitization in the present case because of the half-life of tocilizumab. Before treatment with tocilizumab, the patient's juvenile arthritis disease activity score (JADAS) 27 was 16.8. Respectively, at weeks 8 and 12 weeks of treatment, the JADAS 27 was 5.8 and 0 , and the American College of Rheumatology Pedi response was 50 and 100 .

sJIA differs from other types of JIA, with prominent systemic clinical features, marked elevation of inflammatory markers, and absence of autoantibodies. Innate immune mechanisms appear to play a central role: overproduction of the inflammatory cytokines of innate immunity is a typical feature of sJIA. A better understanding of the role of these cytokines has been translated into therapeutic approaches. Indeed, remarkable results have been observed with IL-1 and IL-6 inhibitors both in clinical trials and in real life [1].

Rapid desensitization enables safe readministration of monoclonal antibodies after hypersensitivity reactions and can be applied when no alternatives are available, although reactions cannot be ruled out.

The recommended rapid desensitization protocols for monoclonal antibodies are applied in 12 steps in 3 solutions. The dose is increased 2- to 2.5-fold in each step [5].

Monoclonal antibodies are rapidly becoming standard therapy in the treatment of a multitude of diseases. For the most part, they are well tolerated. However, a subset of patients experience hypersensitivity reactions following the administration of these drugs. The symptoms of hypersensitivity reactions range from mild (fever, rash, pruritus) to severe, including life-threatening anaphylaxis [6].

Tocilizumab is a recombinant humanized anti-IL-6 receptor monoclonal antibody, which is administered monthly by intravenous infusion and prevents IL-6 signal transduction [7].

Although hypersensitivity reactions in tocilizumab are extremely rare, clinicians must always keep anaphylaxis in mind [8]. It is important to adhere to the treatment plan. We recommend desensitization rather than withdrawal of therapy in patients who respond well to the drug or have no other therapeutic option.

The first report of a child being desensitized to tocilizumab was a girl with Still disease [9]. There are reports of successful desensitization with tocilizumab in adults [10].

Anaphylaxis is an immediate reaction that can be lifethreatening, and, once it occurs, the risk of recurrence is higher if the patient is exposed to the same allergen. The best course of action for such patients is to discontinue the drug and to replace it with an alternative. However, desensitization protocols are used in cases where there is no alternative treatment or the effectiveness of alternative treatment is significantly lower. In desensitization, the goal is to achieve temporary unresponsiveness to the drug that induces anaphylaxis. The key to successful desensitization is to administer increasing doses of medication until the cumulative dose is reached. With desensitization protocols, patients can use medications that cause anaphylaxis.

We present the case of a patient who experienced anaphylaxis with tocilizumab and for whom no alternative drugs were available. In conclusion, our clinical experience indicates that desensitization protocols can be used in patients who experience anaphylaxis with tocilizumab. 


\section{Funding}

The authors declare that no funding was received for the present study.

\section{Conflicts of Interest}

The authors declare that they have no conflicts of interest.

\section{References}

1. Pardeo M, Bracaglia C, De Benedetti F. Systemic juvenile idiopathic arthritis: New insights into pathogenesis and cytokine directed therapies. Best Pract Res Clin Rheumatol. 2017;31:4:505-16.

2. Al-Shakarchi I, Gullick NJ, Scott DL. Current perspectives on tocilizumab for the treatment of rheumatoid arthritis: a review. Patient Prefer Adherence. 2013;4;7:653-66.

3. Sieper J, Porter-Brown B, Thompson L, Harari O, Dougados M. Assessment of short-term symptomatic efficacy of tocilizumab in ankylosing spondylitis: results of randomised, placebocontrolled trials. Ann Rheum Dis. 2014;73:1:95-100.

4. Cox LS, Sanchez-Borges M, Lockey RF. World Allergy Organization Systemic Allergic Reaction Grading System: Is a Modification Needed? J Allergy Clin Immunol Pract. 2017; 5(1):58-62.e5.

5. Brennan PJ, Rodriguez Bouza T, Hsu Fl, Sloane DE, Castells MC. Hypersensitivity reactions to mAbs: 105 desensitizations in 23 patients, from evaluation to treatment. J Allergy Clin Immunol. 2009;124:6:1259-66.

6. Chung $\mathrm{CH}, \mathrm{O}^{\prime}$ Neil $\mathrm{BH}$. Infusion reactions to monoclonal antibodies for solid tumors: immunologic mechanisms and risk factors. Oncology (Williston Park). 2009;23(2 Suppl 1):14-7.

7. Mima T, Nishimoto N. Clinical value of blocking II-6 receptor. Curr Opin Rheumatol. 2009;21;3:224-30.

8. Ogata A, Amano K, Dobashi H, Inoo M, Ishii T, Kasama T. et al. MUSASHI Study Investigators. Longterm Safety and Efficacy of Subcutaneous Tocilizumab Monotherapy: Results from the 2-year Open-label Extension of the MUSASHI Study. J Rheumatol. 2015;42:5:799-809.

9. Justet A, Neukirch C, Poubeau P, Arrault X, Borie R, Dombret $M C$, Crestani B. Successful rapid tocilizumab desensitization in a patient with Still disease. J Allergy Clin Immunol Pract. 2014;2:5:631-2.

10. Ye W, Fifield MC, Mayhew A, Nasser S, Östör A. Successful tocilizumab desensitization in an adult with juvenile idiopathic arthritis. Scand J Rheumatol. 2016;45:1:75-6.

Manuscript received July 7, 2018; accepted for publication September 3, 2018.

Murat Cansever

Erciyes University, Faculty of Medicine Department of Pediatrics, Division of Allergy

Kayseri/Turkey

E-mail: mcansever66@hotmail.com 